\title{
Optional word order in wh-questions in two Norwegian dialects: a diachronic analysis of synchronic variation
}

\section{Marit R. Westergaard}

\begin{abstract}
Based on a corpus of spontaneous production data, this paper compares the word order of wh-questions in two Norwegian dialects, Kåfjord and Tromsø. While the choice of word order (V2 or non-V2) in Tromsø is dependent on information structure, the Kåfjord speakers produce considerably more non-V2 in questions with monosyllabic $w h$-elements. The majority of questions with multisyllabic wh-constituents, on the other hand, occurs with V2. This synchronic variation is given a diachronic analysis within a Split-CP model of clause structure and a cue-based approach to acquisition and change, where an economy principle (head preference) also plays an important role. Furthermore, an information structure drift from V2 to non-V2 is argued to cause the cue for verb movement to fall below a critical level in the input to children, the result being that V2 only survives in lexically marked cases in Kåfjord, i.e. with the verb 'be'.
\end{abstract}

Keywords cue-based acquisition and change, frequency of input, head preference principle, information structure, Split-CP model

Marit $R$. Westergaard, Department of Language and Linguistics (CASTL), University of Troms $\phi$, 9037 Troms $\phi$,Norway.E-mail: Marit.Westergaard@hum.uit.no

\section{INTRODUCTION}

In this paper I compare and discuss the word order of $w h$-questions in two Norwegian dialects spoken in the northern part of the country, the Troms $ø$ dialect as it is described in Westergaard (2003) and some new data from the Kåfjord dialect. Although Norwegian in general requires verb second (V2) word order, both of these dialects allow a word order without verb movement in wh-questions (non-V2). The new data from the Kåfjord dialect presented in this paper consist of the spontaneous speech of two adults from an acquisition corpus, altogether approximately $1000 \mathrm{wh}$-questions. It is shown that, while non-V2 word order is produced in an overwhelming majority of questions with monosyllabic $w h$-constituents, this word order is extremely infrequent in questions with longer $w h$-elements. This is compared to findings from the Troms $\varnothing$ dialect, where non-V2 is only allowed in questions with monosyllabic $w h$-words. The 
differences between the dialects of Kåfjord and Troms $\emptyset$ are discussed in terms of a possible diachronic development from $\mathrm{V} 2$ to non-V2, where some sociolinguistic factors are also taken into account. The analysis relies heavily on an economy principle proposed in van Gelderen (2004a, b) and Lightfoot's (1999, forthcoming) cue-based theory of language acquisition and change, where the frequency of cues in the input to children plays an important role.

The paper is organized in the following way: In the next section, I outline the word order of Norwegian, focusing on three dialect types discussed in Westergaard \& Vangsnes (2005). In section 3 I present the Kåfjord data and make a comparison with the findings from the Troms $\varnothing$ dialect in Westergaard (2003). I also provide some additional Troms $\varnothing$ data from K. Westergaard (2005), a small study that has investigated $w h$-questions produced by four teenage speakers. In section 4 I provide an analysis of the synchronic variation in terms of a possible historical development of word order, and add a sociolinguistic perspective. Section 5 contains a summary and conclusion.

\section{THE WORD ORDER OF NORWEGIAN}

Norwegian is a so-called asymmetric verb second (V2) language, which means that the finite verb appears in second position in all main clauses. V2 word order is standardly assumed to be the result of verb movement to the $\mathrm{C}$ position of the clause, see e.g. Vikner (1995). This is illustrated by the non-subject-initial declarative in (1), where the verb has moved across the subject. The V2 requirement also holds in wh-questions in Standard Norwegian, as is shown by the word order of (2).

(1) Konserter går jeg ofte på./*Konserter jeg går ofte på. (Standard Norwegian) concerts go I often on

'Concerts I often go to.'

(2) Hvilken konsert skal du på?/*Hvilken konsert du skal på?

which concert shall you on

'Which concert are you going to?'

However, it is relatively well known that many dialects of Norwegian do not have a strict V2 requirement in $w h$-questions. This has been discussed by many linguists over the years, e.g. Åfarli (1985, 1986), Nordgård (1985), Taraldsen (1985, 1986), Lie (1992), Fiva (1996), Nilsen (1996), Rice \& Svenonius (1998), Westergaard (2003), Vangsnes (2004) and Westergaard \& Vangsnes (2005). In Westergaard \& Vangsnes (2005), three dialect types of Norwegian are discussed and compared: (i) Standard Norwegian, which has a strict V2 requirement in all wh-questions, (ii) the Troms $\varnothing$ dialect, which optionally allows non-V2 word order in questions with monosyllabic 
wh-elements, but requires V2 in questions with longer wh-elements; and (iii) the Nordmøre dialect, which has optional V2 in all types of wh-questions. Examples of different $w h$-questions in the Troms $\emptyset$ and Nordmøre dialects are provided in (3)-(6). In this paper these three dialect types will be argued to represent different stages of a diachronic development from V2 to non-V2 word order.

(3) Ka drikk du idag?/Ka du drikk i dag?

(Troms $\varnothing)$

what drink you today

'What are you drinking today?'

(4) Korfor kommer han ikkje?/*Korfor han ikkje kommer?

why comes he not

'Why isn't he coming?'

(5) Kåin lika du best?/Kåin du lika best?

(Nordmøre)

who like you best

'Who do you like best?'

(6) Kåles bil kjøpte du?/Kåles bil du kjøpte?

which car bought you

'Which car did you buy?'

(From Åfarli 1986:98, 100)

There does not seem to be any difference in meaning between the two word orders in (3) when the sentences are considered in isolation. In Westergaard (2003), some spontaneous speech data from one adult speaker of the Troms $\emptyset$ dialect are investigated, and it is argued that there is a distinction between the two word orders in discourse. The speech sample has been taken from an acquisition study, where the adult speaker is one of the investigators (abbreviated INV in the examples). ${ }^{1}$ This adult speaker is found to produce a considerable number of wh-questions with both word orders, with a frequency of $45.3 \%$ V2 and $54.7 \%$ non-V2. More importantly, the choice between the two word orders is argued not to be random, but dependent on the information structure of the sentence: Non-V2 word order is preferred if the subject is informationally given, while V2 is chosen if the subject conveys new information. ${ }^{2}$ This is reflected in certain statistically significant preference patterns for subject and verb types in the two constructions: V2 word order is typically chosen when the verb is vare 'be' and the subject is a full DP (in kor-questions, 'where') or the pronoun det 'it, that', normally functioning as a demonstrative (in questions with the other two monosyllabic question words, $k a$ 'what' and kem 'who'), see the examples in (7) and (9). Non-V2 word order, on the other hand, mainly occurs when the subject is a personal pronoun and the verb any other verb than 'be', as illustrated in (8) and (10). This is summarized in (11).

(7) kor er søppelmannen henne? (INV, file Ole.20)

(Tromsø)

where is garbage.man.DEF LOC

'Where is the garbage man?' 
(8) kor du har søppelbilen din henne \# huh? (INV, file Ole.20) where you have garbage.truck your LOC

'Where do you have your garbage truck?'

(9) ka er det der for noenting?

(INV, file Ole.13)

what is that there for something

'What is that?'

(10) $\mathrm{ka} \mathrm{du}$ trur det er for nokka?

(INV, file Ole.16) what you think it is for something

'What do you think it is?'

(11) a. Statistically significant patterns

V2: $\quad$ Subject: DP/dem. pronoun Verb: be

Non-V2: Subject: personal pronoun Verb: all other verbs

b. Generalization

V2 with informationally new subjects (often a full DP)

Non-V2 with informationally given subjects (often a personal pronoun)

What we see in the above examples is that the choice of word order in actual speech production follows the well-known pragmatic principles of end focus and end weight (see e.g. Firbas 1992). While new and heavier subjects tend to appear in sentences with V2 word order (with the subject following the verb), informationally given and typically shorter subjects (often pronouns) appear in sentences with nonV2, i.e. in a position where the subject precedes the verb.

The Kåfjord speech data that I present in this paper are taken from the same acquisition corpus as the sample of Troms $\varnothing$ data and consist of the spontaneous production of the parents of one of the children in the study. Kåfjord is an area approximately 150 kilometers north of Troms $\emptyset$. A dialect spoken in an area directly north of Kåfjord again, the municipality of Nordreisa, has been found to be similar to the Nordmøre dialect in that it allows non-V2 word order in any type of whquestion, see Nilsen (1996). She argues that this lack of V2 is a result of language contact with Finnish and Saami in this area, i.e. languages that are not V2. ${ }^{3}$ As Kåfjord has a similar language history, I decided to investigate the data of the parents in order to see if this type of non-V2 word order was attested in their speech and if so, whether the information structure patterns found for the Troms $\emptyset$ speaker would be repeated also in questions with longer $w h$-constituents. The speech sample investigated here shows that the Kåfjord speakers do produce the same word order in wh-questions as Nilsen (1996) attested for the Nordreisa dialect. Surprisingly, however, the proportion of V2 vs. non-V2 in questions with monosyllabic whconstituents differs considerably from that produced by the Troms $\emptyset$ speaker, and the patterns of information structure are only partly confirmed. The questions with longer wh-elements, on the other hand, exhibit strikingly different proportions of the 
two word orders. It is these findings that give rise to the diachronic analysis provided in section 4.

\section{THE KÅFJORD DATA}

\subsection{The study}

The sample of adult speech from the Kåfjord dialect is taken from the recordings made with the girl Ann in the acquisition corpus. Both parents grew up in Kåfjord, but they have lived most of their adult lives in Tromsø. This means that they are possibly not typical representatives of the Kåfjord dialect, and this may be problematic from a sociolinguistic perspective. However, the main focus of this paper is not a description of the Kåfjord dialect per se, but a presentation of the variation that can be found in V2 grammars and an analysis of this in a diachronic perspective.

The Ann corpus consists of 21 files, recorded at two- to three-week intervals when the child was between the age of approximately 1;9 and 3. The adult production consists of conversations with the child (mainly) as well as with the investigator, and it is in that sense comparable to the adult sample of the Troms $\varnothing$ dialect investigated in Westergaard (2003), which consists of 10 files of recordings with the child Ole (files Ole.13-22, age of child approximately 2;6-3). The mother of the child is present during the recordings more often than the father, which is reflected in a considerably higher number of wh-questions produced by her in the corpus. In the files Ann.0121 , the father produces altogether 127 complete non-subject $w h$-questions, while the mother produces as many as $864 .^{4}$ An overview of the different types is provided in Table 1.5

\begin{tabular}{|l|l|l|l|}
\hline Type of $\boldsymbol{w h}$-element & Female (b. 1957) & Male (b. 1952) & Total \\
\hline Ka 'what' & 527 & 88 & 615 \\
\hline Kor 'where' & 131 & 17 & 148 \\
\hline Kem 'who' & 113 & 13 & 126 \\
\hline Korfor 'why' & 30 & 1 & 31 \\
\hline Korsen 'how' & 13 & 5 & 18 \\
\hline Katti 'when' & 2 & 0 & 2 \\
\hline Long wh-phrase & 47 & 3 & 50 \\
\hline Total & $\mathbf{8 6 3}$ & $\mathbf{1 2 7}$ & $\mathbf{9 9 0}$ \\
\hline
\end{tabular}

Table 1. Overview of $w h$-questions produced by the adults speaking Kåfjord dialect, in the files Ann.01-21.

In the next section I present the adult data from the corpus on questions with the monosyllabic question words, $\mathrm{ka}$ 'what', kor 'where' and kem 'who', and provide a comparison with the Troms $\emptyset$ data. I then consider the production of the two word orders in questions with longer wh-constituents in the Kåfjord data, in section 3.3. 


\subsection{The word order of questions with monosyllabic wh-constituents}

Table 2 gives an overview of the number of questions with monosyllabic wh-elements produced with V2 and non-V2 word order by the two adult speakers from Kåfjord. As we see, there is considerably more non-V2 than V2, 85.2\% produced by the mother and as much as $97.5 \%$ produced by the father, who only produces a total of three questions with verb movement in the sample. According to Nilsen (1996), male speakers in Nordreisa are more likely to accept non-V2 word order in the grammaticality judgement experiments that she has carried out, and the fact that the father produces even less V2 in this study than the mother suggests that this is also the case in Kåfjord. In a recent conversation with the mother I was also told that her husband was more 'true' to the dialect than she was.

\begin{tabular}{|l|l|r|l|l|}
\hline \multirow{2}{*}{ Wh-word } & \multicolumn{3}{|l|}{ Female speaker } & \multicolumn{2}{l|}{ Male speaker } \\
\cline { 2 - 5 } & V2 & Non-V2 & V2 & Non-V2 \\
\hline Ka 'what' & $46(8.7 \%)$ & $481(91.3 \%)$ & $1(1.1 \%)$ & $87(98.9 \%)$ \\
\hline Kor 'where' & $23(17.6 \%)$ & $108(82.4 \%)$ & 0 & $17(100 \%)$ \\
\hline Kem 'who' & $45(39.8 \%)$ & $68(60.2 \%)$ & $2(15.4 \%)$ & $11(84.6 \%)$ \\
\hline Total & $\mathbf{1 1 4}(\mathbf{1 4 . 8 \% )}$ & $\mathbf{6 5 7 ( 8 5 . 2 \% )}$ & $\mathbf{3 ( 2 . 5 \% )}$ & $\mathbf{1 1 5 ( 9 7 . 5 \% )}$ \\
\hline
\end{tabular}

Table 2. The number of occurrences of $\mathrm{V} 2$ and non-V2 word order in wh-questions with monosyllabic question words, produced by the adults in the Kåfjord speech sample.

As mentioned in section 2, the corresponding figures from the adult speaker of the Troms $\varnothing$ dialect investigated in Westergaard (2003) are an overall proportion of $45.3 \%$ V2 vs. $54.7 \%$ non-V2. This means that there is a striking difference between the two dialects with respect to the frequency of the two word orders, non-V2 being considerably more common in the Kåfjord dialect. However, the relative frequency across the three monosyllabic question words is the same in the two data samples, with non-V2 word order being clearly more common with the question word $\mathrm{ka}$ 'what', while V2 occurs most frequently with the question word kem 'who'. The similarities between the Troms $\varnothing$ speaker and the two Kåfjord speakers with respect to the proportion of V2 and non-V2 with the three question words are illustrated in Figure 1.

\subsection{The word order of questions with multisyllabic wh-constituents}

In this section I present the Kåfjord data on questions with multisyllabic whconstituents. As we saw in Table 1 in section 3.1, there are far fewer questions of this type in the corpus, 92 produced by the mother and as few as 9 produced by the father. Table 3 provides an overview of the word order produced with the different $w h$-elements by the two speakers. 


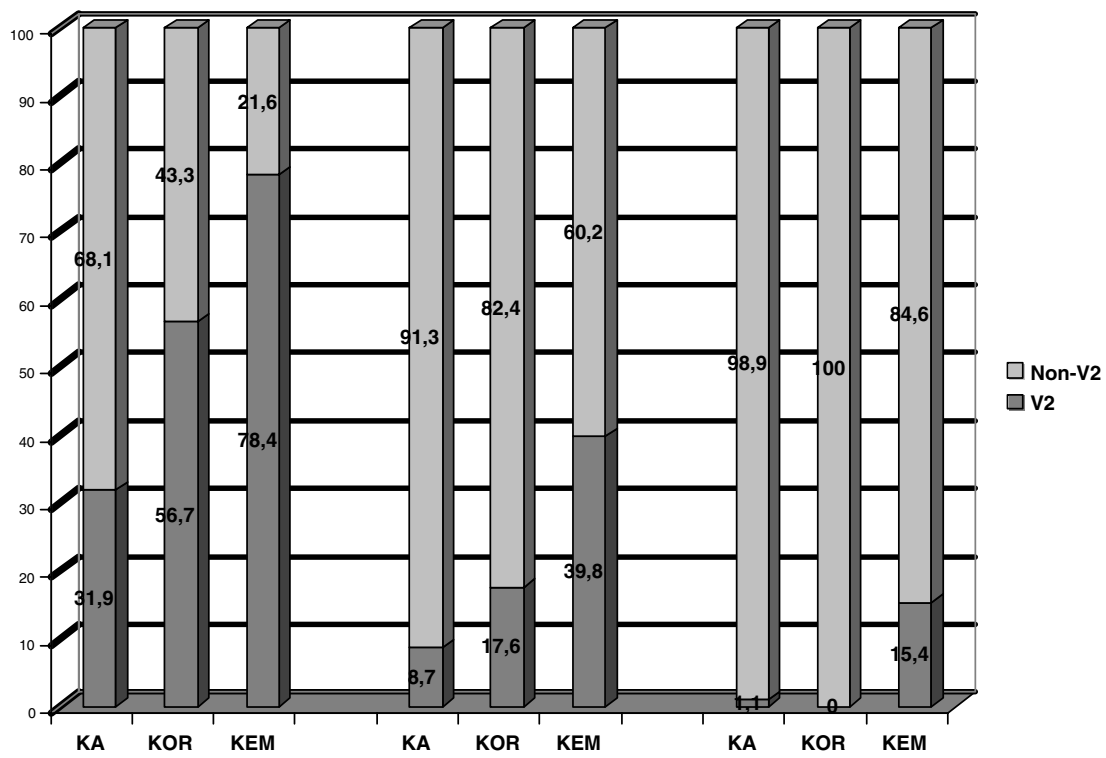

Figure 1. The percentage of V2 vs. non-V2 word order in questions with monosyllabic whelements in the Tromsø dialect (first set of columns), the female Kåfjord speaker (second set) and the male Kåfjord speaker (third set).

\begin{tabular}{|l|l|l|l|l|}
\hline \multirow{2}{*}{ Question type } & Female speaker & \multicolumn{2}{l|}{ Male speaker } \\
\cline { 2 - 5 } & V2 & Non-V2 & V2 & Non-V2 \\
\hline Korfor 'why' & $24(80 \%)$ & $6(20 \%)$ & 1 & 0 \\
\hline Korsen 'how' & $10(76.9 \%)$ & $3(23.1 \%)$ & 0 & 5 \\
\hline Katti 'when' & $2(100 \%)$ & 0 & 0 & 0 \\
\hline Long wh-phrase & $43(91.5 \%)$ & $4(8.5 \% \%)$ & 2 & 1 \\
\hline Total & $\mathbf{7 9 ( 8 5 . 9 \% )}$ & $\mathbf{1 3 ( 1 4 . 1 \% )}$ & $\mathbf{3}$ & $\mathbf{6}$ \\
\hline
\end{tabular}

Table 3. Overview of questions with multisyllabic $w h$-constituents produced by the Kåfjord dialect speakers, in the files Ann.01-21.

The most striking finding presented in Table 3 is the fact that V2 word order is much more frequent than non-V2 in questions with multisyllabic wh-constituents. Considering the mother's data only, the proportion of V2 vs. non-V2 is exactly reversed compared to the finding for the monosyllabic question words presented in Table 2. While the mother produces $85.9 \%$ V2 word order and $15.1 \%$ non-V2 in questions with the multisyllabic $w$-elements, the percentages for the monosyllabic $w h$-words were $14.8 \%$ V2 vs. $85.2 \%$ non-V2. Although the father produces more non-V2 than V2 also in this case, the numbers for his production are too small to be reliable, and three of the five cases of non-V2 with the question word korsen 'how' are variations of the same question uttered with only a few lines in between, as illustrated 
in (12). ${ }^{6}$ Nevertheless, this suggests that there may exist a more conservative version of the dialect which has more non-V2 word order than what is attested in the female speaker's data.

(12) korsn pappa skal gjøre?

(FAT, file Ann.06, line 1524)

how daddy shall do

korsn æ skal gjøre?

(line 1528)

how I shall do

korsn pappa skal gjøre?

(line 1534)

The figures in Table 3 also give a slight indication that non-V2 word order may be more frequent with the disyllabic question words than with the longer $w h$-phrases, an example of which is provided in (13). This is discussed in section 3.6 below. Needless to say, there are too few examples in the corpus to be able to make a strong claim about this, but the few questions of these types produced by the father also support a certain word order distinction between sentences such as (12) and (13).

(13) kem hos du har vært?

(MOT, file Ann.21)

who by you have been

'Whose house have you been at?'

\subsection{Some additional Tromsø data}

For comparison, I will also consider some additional data from the Troms $\varnothing$ dialect. K. Westergaard (2005) provides the results of a small investigation of the word order in wh-questions produced by four 18-year-old speakers, three females and one male. These speakers are all born in 1986, which means that they are thirty years younger than the adult speaker investigated in Westergaard (2003). Based on a sample of approximately $200 w h$-questions collected in an elicitation experiment, $\mathrm{K}$. Westergaard finds that all the youngsters produce considerably more V2 word order than the adult in questions with monosyllabic $w h$-elements, especially the three girls. ${ }^{7}$ This is illustrated by the figures in Table 4, which shows that the overall proportion of $\mathrm{V} 2$ word order is as high as $69 \%$.

\begin{tabular}{|l|l|c|}
\hline Wh-word & V2 & Non-V2 \\
\hline$K a$ 'what' & $25(59.5 \%)$ & $17(40.5 \%)$ \\
\hline Kor 'where' & $22(75.9 \%)$ & $7(24.1 \%)$ \\
\hline Kem 'who' & $11(84.6 \% \%)$ & $2(15.4 \%)$ \\
\hline Total & $\mathbf{5 8 ( 6 9 \% )}$ & $\mathbf{2 6 ( 3 1 \% )}$ \\
\hline
\end{tabular}

Table 4. The occurrences of V2 and non-V2 word order in questions with monosyllabic wh-words, produced by three girls (born 1986) in K. Westergaard's (2005) study. 


\begin{tabular}{|l|l|l|}
\hline DIALECTS/SPEAKERS & V2 & Non-V2 \\
\hline Tromsø dialect, 3 female speakers (b. 1986) & $69 \%$ & $31 \%$ \\
\hline Troms $ø$ dialect, 1 female speaker (b. 1956) & $46 \%$ & $54 \%$ \\
\hline Kåfjord dialect, 1 female speaker (b. 1957) & $15 \%$ & $85 \%$ \\
\hline
\end{tabular}

Table 5. Three different V2 grammars in wh-questions in Norwegian dialects.

When the three monosyllabic question words are considered individually, however, we find exactly the same frequency patterns as for the adult speakers, with non-V2 word order occurring most often with the question word $\mathrm{ka}$ 'what' (40.5\%), while V2 is most frequent with the question word kem 'who' (84.6\%), cf. Figure 1 above. The fact that this pattern is visible even when small numbers are involved, as in K. Westergaard's study, indicates that this is part of a general tendency in the language.

Comparing only the female speakers in the three data sets (for sociolinguistic reasons), we thus find that we have what looks like three different V2 grammars attested in Norwegian dialects, as illustrated in Table 5: A truly mixed grammar (Troms $\emptyset$ adult), one where there is a clear predominance of non-V2 (Kåfjord) and one where there is a predominance of V2 (young Troms $\emptyset$ speakers).

This is very similar to different percentages of V2 that have been attested in nonsubject-initial declaratives in the history of English. In Westergaard (forthcoming) I discuss a 70\% V2 grammar of Old English, a 50/50 grammar of Early Middle English and a 30\% V2 grammar of Late Middle English, and I argue that this historical development can be explained in terms of language acquisition. ${ }^{8}$ In Westergaard (2005b) I also argue that the different proportions of V2 in the history of English reflect changing I-language grammars in different generations of speakers. This means that gradual development over several hundred years does not simply represent (stylistic) changes in the E-language, as is often argued in the work of Lightfoot (e.g. 1999, forthcoming) or Hróarsdóttir (e.g. 2002, 2004), see also Hinterhölzl (2005). These E-language changes eventually result in the resetting of a parameter, which corresponds to a 'catastrophic' change, in the terminology of Lightfoot (1999), in the I-language grammar. Instead, I argue for an interpretation of gradualism as a result of changes in several microparameters, i.e. as a result of 'many small catastrophes'. This is the approach that I will argue for also for the Norwegian dialect data discussed in this article.

However, the figures in Table 5 could also be the result of random differences, dependent on sociolinguistic or perhaps only stylistic factors, not reflecting truly different I-languages of the speakers. Therefore, we need to investigate if there is a substantial difference between the three (groups of) speakers, and in this respect it is relevant to consider the subject and verb types used with the two constructions. This should reveal whether there are real word order differences between the dialects or 
whether the varying proportions of V2 could simply be due to the Kåfjord speaker producing a higher number of wh-questions with informationally given subjects in the corpus than the adult Troms $\emptyset$ speaker, and the opposite being the case for the recordings of the young Troms $\varnothing$ speakers. This will be the topic of the next section.

\subsection{Subject and verb types in V2 and non-V2 constructions}

Recall from section 2 that there were clear preference patterns found in the adult Troms $\varnothing$ data for subject and verb types used with the two word orders. V2 is chosen in $w h$-questions when the verb is vare 'be' and the subject a full DP (with the question word kor 'where') or the (normally demonstrative) pronoun det (with the other two question words), while non-V2 tends to occur when the subject is a personal pronoun such as $d u$ 'you' or han 'he' and the verb is any other verb than 'be'. In Table 6, I provide the information on subject and verb choice with the two word orders in $w h$-questions in the Troms $\varnothing$ dialect (figures based on similar tables in Westergaard 2003), and we see that the production of V2 vs. non-V2 clearly clusters in the two relevant cells. Table 7 displays the corresponding figures from the Kåfjord dialect for the mother's data only.

\begin{tabular}{|l|l|l|l|c|}
\hline \multirow{2}{*}{$\begin{array}{l}\text { Subject/Verb } \\
\text { Types }\end{array}$} & \multicolumn{2}{|l|}{ V2 } & Non-V2 \\
\cline { 2 - 5 } & vaere 'be' & Other V & vare 'be' & Other V \\
\hline Full DP/det & 128 & 5 & 27 & 19 \\
\hline Pronoun & 1 & 2 & 4 & 114 \\
\hline
\end{tabular}

Table 6. Subjects and verbs in wh-questions in the Tromsø dialect, adult female speaker.

\begin{tabular}{|l|l|l|l|c|}
\hline \multirow{2}{*}{$\begin{array}{l}\text { Subject/Verb } \\
\text { Types }\end{array}$} & \multicolumn{2}{|l|}{ V2 } & Non-V2 & \\
\cline { 2 - 5 } & vaere & Other V & vaere & Other V \\
\hline Full DP/det & 106 & 3 & $\mathbf{1 4 0}$ & 97 \\
\hline Pronoun & 3 & 2 & 19 & 401 \\
\hline
\end{tabular}

Table 7. Subjects and verbs in wh-questions in the Kåfjord dialect, female speaker.

What we see from these tables is that the subject and verb preferences for V2 word order found in the speech sample of the Troms $\varnothing$ dialect are also attested in the Kåfjord data. Typical examples from the Kåfjord sample are illustrated in (14)-(16). That is, V2 is mainly attested with the verb vare 'be' in all cases and the subject tends to be a full DP with the question word kor 'where', as shown in (14), while it is generally the pronoun det 'it, that' with the other two question words, see (15) and (16). When non-V2 word order is chosen the subject is often a personal pronoun and the verb any other verb than 'be', as in the Troms $\emptyset$ dialect. This is illustrated in examples (17)-(19). For comparison with the Troms $\emptyset$ speech sample, see examples (7)-(10) above. 
(14) kor er Ole Brumm henne?

(MOT, file Ann.01)

where is Ole Brumm LOC

'Where is Winnie the Pooh?'

(15) ka er det der for nokka?

(MOT, file Ann.01)

what is that there for something

'What is that?'

(16) kem var det vi snakka med?

(MOT, file Ann.04)

who was it we talked with

'Who was it we were talking to?'

(17) kor du gikk hen?

(MOT, file Ann.01)

where you went LOC

'Where did you go?'

(18) $\mathrm{ka} \mathrm{du}$ sa for nokka?

(MOT, file Ann.04)

what you said for something

'What did you say?'

(19) kem du snakka med?

who you talked with

'Who were you talking to?'

However, when we consider the non-V2 part of Table 7, we see that the cells for all subject and verb combinations are filled, and moreover, that the typical V2 pattern of subject and verb choice is even more often found with non-V2 word order in the Kåfjord dialect (figure in bold in Table 7, i.e. 140 examples with non-V2 vs. 106 with V2). This means that in addition to typical examples such as the ones illustrated in (17)-(19), non-V2 may occur with any subject and verb combination, also the typical V2 pattern with vare 'be' and full DP subjects (with kor 'where') or the pronoun det (with the other two question words). This is shown in examples (20)-(22).

(20) kor dukka sin sko er?

(MOT, file Ann.04)

where doll POSS shoe is

'Where is the doll's shoe?'

(21) ka det er for nokka?

(MOT, file Ann.01)

what it is for something

'What is it?'

(22) kem det er sin sokk?

(MOT, file Ann.04)

who it is POSS sock

'Whose sock is it?'

This finding indicates that the Kåfjord dialect is in fact different from the dialect of Troms $\varnothing$ in this respect. It seems that non-V2 is the default word order in the Kåfjord dialect, in that it may appear with any type of verb and subject combinations, 


\begin{tabular}{|l|l|l|l|c|}
\hline \multirow{2}{*}{$\begin{array}{l}\text { Subject/Verb } \\
\text { Types }\end{array}$} & \multicolumn{2}{|l|}{ V2 } & Non-V2 \\
\cline { 2 - 5 } & vaere & Other V & vare & Other V \\
\hline Full DP/det & 12 & 8 & 0 & 2 \\
\hline Pronoun & 6 & 22 & 2 & 23 \\
\hline
\end{tabular}

Table 8. Subjects and verbs in wh-questions in the Tromsø dialect, three young female speakers (based on data in K. Westergaard 2005).

while V2 survives only in the typical cases. Furthermore, it could also be noted that both Kåfjord speakers seem to avoid V2 word order, as they have a tendency to extrapose heavy subjects and leave a pronominal dummy behind, as shown in (23). In this way they preserve the typical pattern for non-V2 word order, also in cases where the subject is informationally new.

(23) ka den hete den dukka du har fått der?

what it is-called that doll you have got there

'What is it called that doll you have got there?'

For comparison I also provide the combined figures for subject and verb types in the production of the three girls in K. Westergaard's (2005) study. In Table 8 we see that the young speakers of the Troms $\varnothing$ dialect display a very different pattern: While non-V2 word order is restricted to the typical cases with pronominal subjects and other verbs than 'be', as was the case in the speech sample from the adult speaker, V2 word order occurs with any type of subject and verb combination. Sentence (24) is an example of V2 word order occurring with the subject and verb combination that is typical of non-V2 in the adult speech sample.

(24) Ka gjør du? (Beate)

what do you

'What are you doing?'

(From K. Westergaard 2005:6)

These findings indicate that the three versions of the dialects in question ARE different with respect to word order. It seems that non-V2 is the default word order in the Kåfjord dialect, in that this word order appears with any type of verb or subject, while V2 survives only in the typical cases, mainly with the verb 'be'. For the young Troms $\varnothing$ speakers, however, it is the V2 word order which is the default, while nonV2 is used only in cases where the subject is informationally given. These findings suggest that the different proportions of $\mathrm{V} 2$ word order displayed in Table 5 do reflect different I-language grammars.

\subsection{Subject and verb types in questions with multisyllabic wh-elements}

In this section I return to the Kåfjord dialect, where both word orders may occur also in questions introduced by longer wh-constituents. Again I focus on the production 


\begin{tabular}{|l|l|l|l|l|}
\hline \multirow{2}{*}{$\begin{array}{l}\text { Subject/Verb } \\
\text { Types }\end{array}$} & V2 & Non-V2 \\
\cline { 2 - 5 } & vaere & Other V & vaere & Other V \\
\hline Full DP & 3 & 8 & 0 & 2 \\
\hline Pronoun & 6 & 19 & 0 & 7 \\
\hline \multirow{2}{*}{ Total } & 9 & 27 & 0 & 9 \\
\cline { 2 - 5 } & $36(80 \%)$ & $9(20 \%)$ & \\
\hline
\end{tabular}

Table 9. Subject and verb types in questions with disyllabic wh-constituents, produced by the female speaker of the Kåfjord dialect, in files Ann.01-21.

\begin{tabular}{|l|l|l|l|l|}
\hline \multirow{2}{*}{$\begin{array}{l}\text { Subject/Verb } \\
\text { Types }\end{array}$} & V2 & Non-V2 & \\
\cline { 2 - 5 } & vaere & Other V & vare & Other V \\
\hline Full DP & 4 & 3 & 0 & 1 \\
\hline Pronoun & 17 & 19 & 0 & $\mathbf{3}$ \\
\hline \multirow{2}{*}{ Total } & 21 & 22 & 0 & 4 \\
\cline { 2 - 5 } & $43(91.5 \%)$ & $4(8.5 \%)$ & \\
\hline
\end{tabular}

Table 10. Subject and verb types in questions with multisyllabic wh-phrases, produced by the female speaker of the Kåfjord dialect, in files Ann.01-21.

of the mother only, as there are so few examples attested in the father's speech. As mentioned in section 3.3, the data suggest that there is a slight difference between the disyllabic question words and longer wh-phrases with respect to the frequency of occurrence of non-V2 word order. I therefore provide the information for the two question types in separate tables. As shown by the figures in Tables 9 and 10, there is a $20 \%$ occurrence of non-V2 with disyllabic question words and only $8.5 \%$ with longer wh-elements, but as the actual numbers are very small, this is merely an indication.

With respect to the subject and verb combinations occurring in sentences with the two word orders, the two question types seem to be relatively similar: While V2 occurs with any type of subject or verb, non-V2 seems to only appear in those cases which have been found to be typical for this word order, i.e. with pronominal subjects and other verbs than vare 'be'. This is illustrated in examples (25)-(27). The full DPs that appear in three of these cases (two in Table 9, one in Table 10) have all been mentioned in previous discourse and are thus clearly given information, as illustrated by the context provided in example (28).

(25) korsen vi kom til Ingunn i dag?

(MOT, file Ann.09)

how we came to Ingunn today

'How did we get to Ingunn's today?'

(26) koffer du går dit bort?

(MOT, file Ann.02)

why you walk there away

'Why are you walking over there?'

(27) kem hos du har fått den?

(MOT, file Ann.01)

who from you have got that

'Who did you get that from?' 
(28)

$$
\begin{array}{rll}
\text { MOT: nei } & \text { kor }[/ /] & \text { ka Eline kan si? } \\
\text { no } & \text { where ... } & \text { what Eline can say }
\end{array}
$$

MOT: huh?

MOT: korsen Eline snakke?

how Eline talks

'How does Eline talk?'

The findings presented in this section indicate that the questions with multisyllabic wh-elements exhibit a very different behavior compared to the questions introduced by monosyllabic question words. Not only is there a reversal of frequencies of the two word orders, approximately $85 \%$ non-V2 with monosyllabic question words and about the same percentage displaying V2 with the multisyllabic wh-elements. It also seems clear that the default word order in the former case is non-V2, while it is V2 in the latter. This is because non-V2 occurs with any subject and verb combination in questions with monosyllabic question words, while the same is the case for V2 word order in questions with longer $w h$-elements. The more special word order appears only in cases when the situation is right for it, i.e. V2 occurs in questions with monosyllabic wh-elements virtually only with the verb vare 'be' and when the subject is the pronoun det or a full DP (see Table 7 in the previous section), while non-V2 in questions with multisyllabic wh-constituents is generally restricted to questions with pronominal subjects and other verbs than 'be' (see Tables 9 and 10).

\section{A POSSIBLE DIACHRONIC ANALYSIS OF THE DIALECT DATA}

\subsection{Introduction}

In the following sections I propose a tentative historical scenario for the development from a V2 to a non-V2 grammar in wh-questions in Norwegian dialects. Important factors for this change are an economy principle in van Gelderen (2004a, b) and a cuebased approach to language acquisition and change (Lightfoot 1999, forthcoming). The former causes a historical drift towards head status of the wh-elements, starting with the monosyllabic question words, which may then move into the head position that the verb normally moves to and thus prevent V2. This is what I have argued has happened in the Troms $\varnothing$ dialect, see also Westergaard (2005a). This may then later spread to the disyllabic question words, while V2 with longer wh-phrases lags behind. Because of the considerably higher frequency of the monosyllabic question words than other wh-elements, at least in the input to children, the overall frequency of V2 will drop. Within Lightfoot's cue-based approach to acquisition and change I argue that when the frequency of the relevant constructions falls below a critical level, 
children will ignore the cue and the result of this will be loss of V2. However, this change in the internalized grammar of speakers will be masked by verb movement still occasionally applying to another head in the CP domain, one which attracts the verb only when the subject is informationally new (Westergaard \& Vangsnes 2005). Finally, an information structure drift towards non-V2 may cause loss of verb movement also to this head position, so that V2 only survives in lexically marked cases, e.g. only with the verb 'be'.

Before I outline this historical development I provide a brief sociolinguistic perspective of the dialect situation in the next section. In section $4.3 \mathrm{I}$ briefly describe a syntactic model for the analysis of word order, generally based on Westergaard \& Vangsnes (2005), and provide a synchronic analysis of the dialect facts. I then discuss a possible diachronic word order development in questions with monosyllabic whwords in section 4.4 and focus on questions with longer $w h$-elements in section 4.5.

\subsection{A sociolinguistic perspective}

As already mentioned in section 2 above, the dialect spoken in an area directly north of Kåfjord (Nordreisa) has been investigated in Nilsen (1996) and Sollid [=Nilsen] (2003). She finds that older speakers in the area accept non-V2 word order to a larger extent than younger people in her study, and she argues that the change occurring in the Nordreisa dialect at the present time goes in the direction of the standard language, i.e. that there is development from non-V2 to V2. Given that the language situation in Kåfjord is the same as in Nordreisa, it is to be expected that the same development is taking place there. This may also be the case in the Troms $\emptyset$ dialect, as a comparison of the adult speaker investigated in Westergaard (2003) with the findings for the teenagers in K. Westergaard's (2005) study reveals a higher production of V2 on the part of the younger speakers. K. Westergaard also suggests that her results could be interpreted as illustrating a development towards more V2 taking place in the Troms $\varnothing$ dialect, which she attributes to a general change in Troms $\emptyset$ in the direction of standard Norwegian. This is of course the opposite of the historical development that I propose in this paper and which I believe represents a natural drift based on economy principles and cue-based acquisition. My interpretation of the results of the investigations reported in Nilsen (1996) and K. Westergard (2005) is therefore that the (natural) development from V2 to non-V2 may be reversed in the two dialects discussed here, due to external, sociolinguistic factors.

In the history of the Kåfjord dialect external factors have presumably taken place in two directions: First, the natural drift has been affected by language contact with non-V2 languages in the area. According to Nilsen (1996) and Sollid (2003) this took place at the beginning of the twentieth century. Unlike Sollid (2003), however, I do not believe that what we see in this dialect area is CAUSED BY language contact; if that were the case, we would not expect to see the different patterns across the individual 
wh-elements that have been presented in this paper. Rather, I would argue that this language contact has increased the occurrences of non-V2 and thus ACCELERATED the process of change that was already underway in the Norwegian dialects that were in contact with Finnish and Saami. But at a later stage this process has been REVERSED by sociolinguistic factors, viz. a pressure to conform to the standard language and other Norwegian dialects in the area.

\subsection{The syntactic model and a synchronic analysis of different dialect types}

In this section I briefly outline a Split-CP approach to word order that will be used to analyze the Norwegian dialect data. This is inspired by, but in many ways different from, the model in Rizzi (1997, 2001). This Split-CP approach was originally developed in Westergaard \& Vangsnes (2005), and used there to account for the word order of the three dialect types introduced in section 2, Standard Norwegian, the Troms $\varnothing$ dialect and the Nordmøre dialect. The model was slightly revised in Westergaard (2005a), where the heads argued to be present in the CP domain are as given in (29). In this model, V2 word order is considered to be the result of verb movement to different heads in the CP domain. In Westergaard (2005a) it is also argued that, apart from certain heads required by UG for clause typing, e.g. the IntP for $w h$-questions or the TopP for declarative clauses, children will only build as much structure in the $\mathrm{CP}$ domain as there is evidence for in the input.

$$
{ }_{\mathrm{CP}}[\mathrm{INT}(\text { errogative) } \quad \text { TOP(ic) } \quad \text { POL(arity) FOC(us) WH FIN(iteness) }
$$

$\mathrm{V} 2$ word order in $w h$-questions in this model is generally due to the presence of an EPP head feature ( $\left.\left[\mathrm{X}^{\circ}{ }_{\mathrm{EPP}}\right]\right)$ on the $\mathrm{Int}^{\circ}$ head, which attracts the verb to this position. The difference between the three dialect types is explained in the following way: While both Standard Norwegian and the Troms $\varnothing$ dialect have the EPP feature on Int $^{\circ}$, this feature is lacking in the Nordmøre dialect. This is illustrated for Standard Norwegian in (30) and the Nordmøre dialect in (32) and accounts for obligatory verb movement in the former dialect type in all wh-questions and the lack of it in the latter. Furthermore, in Westergaard (2005a), following ideas in van Gelderen (2004a, b), it is suggested that the monosyllabic question words may move as heads in the Troms $\varnothing$ dialect, thus occupying $\operatorname{Int}^{\circ}$ and blocking verb movement to this head position in those cases. This is due to a Head Preference principle, which simply states that it is more economical to move as a head than a phrase. Van Gelderen (2004b) gives numerous examples of elements that have changed status from phrase to head in the course of historical development, e.g. relative that in English. I argue that the monosyllabic wh-elements in the Troms $\emptyset$ dialect have been affected by this Head Preference drift and undergone a reanalysis as heads. This constitutes the first stage of the change from a V2 to a non-V2 grammar. ${ }^{9}$ The longer $w h$-constituents, on the 
other hand, move to SpecIntP, and the head position of this projection is therefore available for the finite verb in such sentences. The situation for the Troms $\emptyset$ dialect is illustrated by the structure in (31). In the following, I will argue that the three dialect types in (30)-(32) represent different stages of a diachronic development from V2 to non-V2 word order in Norwegian dialects.

(30)

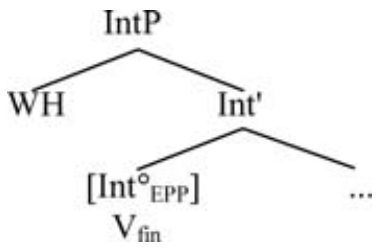

(31)

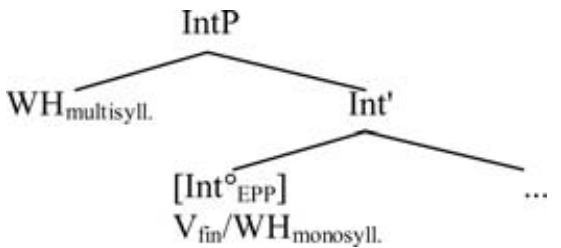

(32)

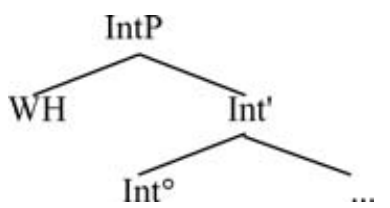

(Standard Norwegian)

$($ Troms $\varnothing)$

(Nordmøre)

In order to explain the optional nature of verb movement in all wh-questions in the Nordmøre dialect and in questions with monosyllabic wh-elements in Troms $\varnothing$, Westergaard \& Vangsnes (2005) propose the existence of another projection in the CP domain, the Foc(us)Phrase. This projection attracts the verb to its head position only in case the subject of the sentence is new information, i.e. [+foc]. In Westergaard (2005a), it is also suggested that, when the subject is informationally given ([-foc]), it is the subject itself that moves to the specifier of the FocP. This means that the FocP attracts informationally light elements and is thus very different from the FocP proposed in the system of Rizzi $(1997,2001)$. This projection is therefore responsible for the effect of information structure seen in the actual production of the two word orders in the adult sample of the Troms $\emptyset$ dialect: As illustrated by examples (7)-(10) in section 2 above, V2 word order tends to be produced when the subject conveys new information, while non-V2 is preferred when the subject is informationally given. The syntactic representations in (33) and (34) show the proposed structures for V2 and non-V2 wh-questions respectively: In the latter case, the FocP attracts a [-foc] subject to its specifier, while in the former case, when the subject conveys new information and has the feature [+foc], the verb (typically a semantically light verb, most often vare 'be') is attracted to the $\mathrm{Foc}^{\circ}$ head. 

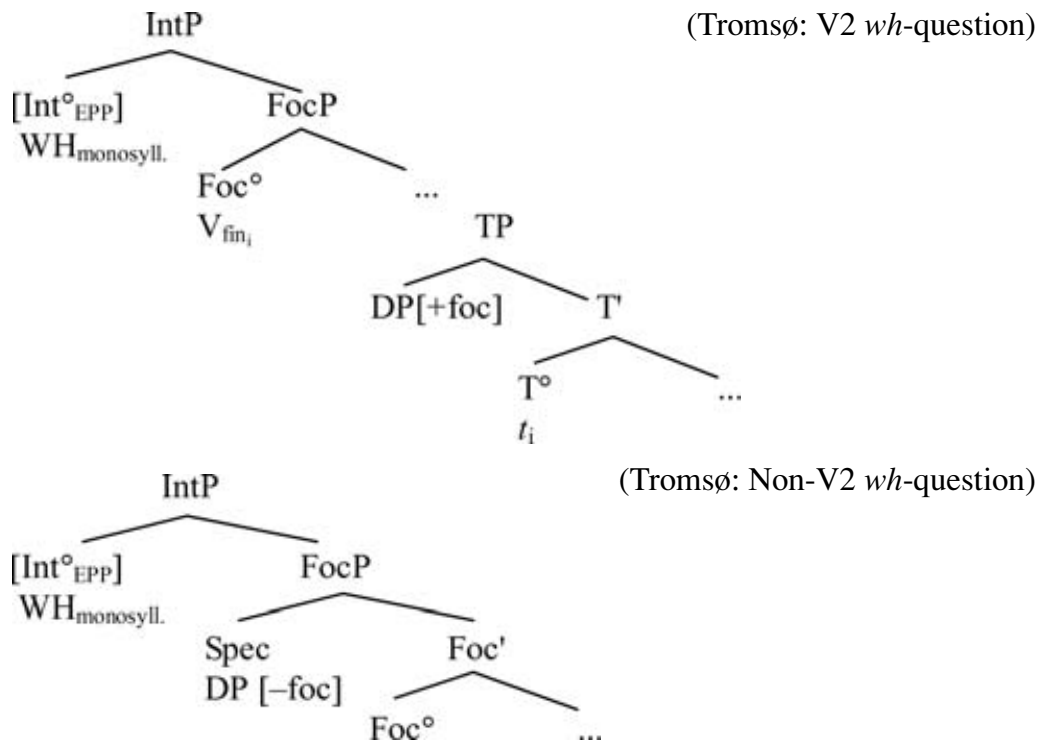

(Tromsø: Non-V2 wh-question)

I will now incorporate the findings from the Kåfjord dialect sample into this system. This dialect is in some way the same as the Nordmøre dialect, in that it allows non-V2 word order in all types of $w h$-questions. Nevertheless, I would argue that it is in fact more similar to the Troms $\emptyset$ dialect with respect to the presence of the EPP feature on the Int $^{\circ}$ head. Given the low frequency of non-V2 in questions with multisyllabic $w h$-elements (disyllabic question words and longer $w h$-phrases), as well as the default nature of V2 in these cases with respect to subject and verb choice, it seems reasonable to assume that there is verb movement to $\operatorname{Int}^{\circ}$ in this dialect. As additional support for this claim comes the fact that when asked for grammaticality judgements, the female speaker of this dialect was very reluctant to even accept non-V2 word order in questions with disyllabic wh-elements, and the questions with longer $w h$-phrases she found ungrammatical (even the ones she had uttered herself). ${ }^{10}$ In comparison, both word orders felt equally natural in questions with monosyllabic question words for this speaker. I would therefore like to conclude that the Kåfjord dialect, as represented by the two speakers investigated here, has the EPP head feature on $\operatorname{Int}^{\circ}$ and (generally) verb movement to this position in questions with multisyllabic $w h$-elements.

The frequent non-V2 word order seen in questions with the short, monosyllabic $w h$-constituents can then be explained in the same way as in the Troms $\varnothing$ dialect: The question words ka, kor and kem ('what', 'where' and 'who') behave as heads with respect to movement and move into Int $^{\circ}$, thus checking the EPP head feature and obviating verb movement to this position.

But how do we then account for the occasional occurrence of V2 in questions with monosyllabic $w h$-elements and the similarly infrequent non-V2 word order in 
questions with longer wh-constituents? And how do we explain the fact that these word orders are restricted to a certain combination of subject and verb types? Given that these subject and verb combinations to a certain extent follow the patterns of information structure that were attested for the Troms $\varnothing$ dialect, it seems reasonable to try to account for them in a similar way, by reference to the FocP. However, this will not be sufficient, and it is therefore necessary to appeal to a theory of language acquisition and language change.

\subsection{Questions with monosyllabic wh-constituents}

In the previous section I suggested that the monosyllabic wh-elements in the Kåfjord dialect behave as heads and move into Int $^{\circ}$, checking the EPP feature on this head. This means that monosyllabic $w h$-words have undergone the same reanalysis from phrase to head as that proposed for the Troms $\emptyset$ dialect, where any V2 word order in these question types must be the result of verb movement to the $\mathrm{Foc}^{\circ}$ head. If this is the case also in the Kåfjord dialect, this would explain why verb movement in these questions occurs only when the subject conveys new information. However, it does not explain why verb movement does not ALWAYS take place when the subject is informationally new. Given the default nature of non-V2 in questions with monosyllabic question words, this word order occurs with all types of subjects, informationally given as well as informationally new ones. Therefore I will argue that verb movement to the Foc ${ }^{\circ}$ head must also have been lost in these cases, as V2 survives only in special cases, i.e. only with the verb 'be'. This means that V2 is no longer part of a productive process in questions with monosyllabic wh-elements in the Kåfjord dialect, and the occurrences that do appear in the data are presumably lexically marked cases (only $14.1 \%$ produced by the female speaker and as little as $2.5 \%$ in the data of the male speaker, see Table 2). Within a cue-based theory of language acquisition and change, the loss of verb movement to the $\mathrm{Foc}^{\circ}$ head can be explained in terms of a drop in frequency of the cue for verb movement.

Despite the language contact facts of the Kåfjord area, I believe that the Kåfjord dialect today should be considered a true Norwegian dialect, directly descended from the version of Norwegian that was in contact with Finnish and Saami at the beginning of the twentieth century. This means that a previous stage of the dialect has presumably once had the same frequencies and conditions for V2 and non-V2 as the Troms $\varnothing$ dialect (and at some point, e.g. Old Norse, the ancestor language was strictly V2). The change from a mixed V2 grammar (with verb movement to $\mathrm{Foc}^{\circ}$ ) to a more or less consistently non-V2 grammar may then have occurred in the following way: When there is optionality in the syntax, the two options will tend to be linked to patterns of information structure (see e.g. Bresnan \& Nikitina 2003 for discussion of the dative construction in English). The result of such syntactic optionality in the case of $w h$-questions in Norwegian is the word order situation in the Troms $\varnothing$ dialect 
(the adult data), where non-V2 is clearly connected to informationally given subjects and V2 to subjects conveying new information. Since subjects in general tend to be given information, this should gradually lead to higher frequencies of non-V2. This is what I call an information structure drift, and which I have argued to be responsible for a similar word order change in the history of English in Westergaard (forthcoming). In Lightfoot's (1999, forthcoming) theory of cue-based acquisition and change, the claim is that for a construction to be acquired, the cue for it must be expressed robustly in the primary linguistic data that children are exposed to. This means that once the frequency of a cue for a particular construction falls below a critical level, it will be ignored by children. The new grammar will develop without this construction, and an I-language change will have occurred.

The frequencies of V2 and non-V2 in questions with monosyllabic question words and the patterns of subject and verb types attested in the data investigated in section 3 above suggest that the loss of verb movement to Foc $^{\circ}$ has already occurred in the Kåfjord dialect. And in such cases, lexically marked remnants of the previous system may exist in the grammar, i.e. in this case certain occurrences of V2 word order with the verb 'be'. Note that this is similar to what is found in present-day English, where inversion in non-subject-initial declaratives still exists with certain verbs, mainly 'be'. According to Birner (1995), from which the following example is taken, this construction is restricted to informationally light verbs, which I would argue is a remnant of a previous stage in the grammar of English which had verb movement to the Foc $^{\circ}$ head. ${ }^{11}$

(From Birner 1995:237)

\subsection{Questions with multisyllabic wh-constituents}

In this section I discuss the word order data in questions with longer wh-constituents in the Kåfjord speech sample, where occasional examples of non-V2 word order are attested. Since I argued in section 4.3 that the Kåfjord dialect must have an $\left[\mathrm{X}_{\mathrm{EPP}}^{\circ}\right]$ feature on the $\mathrm{Int}^{\circ}$ head, there should generally be verb movement to this position. It is therefore necessary to account for non-V2 word order by appealing to something that blocks this type of verb movement. In the questions with monosyllabic whconstituents, it is the status of these elements as heads that causes the lack of verb movement. In Westergaard \& Vangsnes (2005), where the crucial aspect of these elements is that they are monomorphemic and therefore non-projecting, it was argued that a historical reanalysis of the disyllabic $w h$-elements is less likely, as their multimorphemic status is relatively transparent, korfor (lit. where+for) 'why', korsen (lit. where+such) 'how' and ka tid (lit. what+time) 'when' (see also Vangsnes 2004).

However, it could be argued that the complex status of these elements has been obscured in many dialects of Norwegian, see e.g. the typical pronunciation in 
the Kåfjord dialect reflected in the spelling often used in the corpus, koffer 'why', korsn 'how' and katti 'when'. Thus, I would like to argue that such a reanalysis is what has taken place in the Kåfjord dialect. In Westergaard (2005a) it is argued that the monosyllabic $w h$-elements of the Troms $\emptyset$ dialect have a dual status, i.e. they may move either as heads or as phrases. This is done to account for the occasional occurrence of questions with V2 word order with subjects that convey given information. It is possible that the disyllabic wh-elements in the Kåfjord dialect also have such a dual status: That is, being heads as well as phrases, they may move EITHER into a head OR a specifier position. When they move as phrases into SpecIntP, the verb will move into $\mathrm{Int}^{\circ}$ and the result is V2 word order, and when they move as heads, verb movement to $\operatorname{Int}^{\circ}$ will be blocked by the presence of the $w h$-element in this head position. This is illustrated in the syntactic representations below, (36) showing the structure of the IntP when the disyllabic wh-word moves as a phrase, while in (37) this element has the status of a head. In the former case, the result will be default V2 word order with any kind of subject, given or new ([+/-foc]). In the latter case, on the other hand, verb movement (to $\mathrm{Foc}^{\circ}$ ) will only take place if the subject of the sentence conveys new information. This ensures that non-V2 word order will only appear with informationally given subjects, which is what the data in Table 7 above indicate.

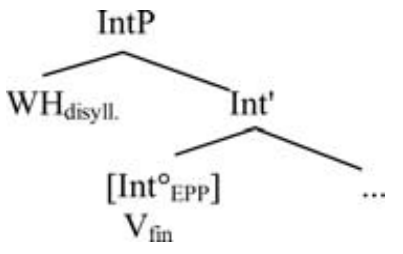

(Kåfjord dialect)

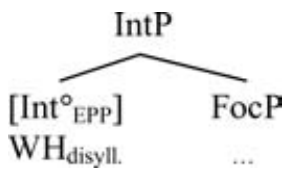

Because of the Head Preference principle proposed in van Gelderen (2004a, b), there will be a historical drift towards the head-like status also of the longer whelements. Nevertheless, in the process of change, it is possible that one must allow for optionality in the system and for a certain difference between speakers with respect to the relative frequency of each pattern. From the data presented in section 3.4, it seems that the male speaker produces more non-V2 than the female speaker in questions with disyllabic $w h$-words. In the analysis proposed here, this would mean that he has a higher preference for the head-like status of these elements than the female speaker, and that his language thus represents a more advanced stage of the historical development from phrase to head. However, according to the sociolinguistic note on the data provided in a previous section, it is the opposite development that 
is actually taking place in the dialect at the present time, and on this view the male speaker produces a more conservative version of the dialect. In this perspective, it is therefore possible to argue that the occurrences of non-V2 word order in questions with disyllabic question words are remnants of a system where a complete reanalysis from phrase to head had already occurred in the dialect.

An explanation in terms of head status is not available for the longer wh-phrases such as kor mange år 'how many years' or ka slags bok 'what kind of book'. Thus, whenever these occur in questions with V2 word order, this must be due to verb movement to $\mathrm{Int}^{\circ}$. The non-V2 word order occurring in questions introduced by these longer $w h$-phrases must therefore be due to a loss of the $\left[\mathrm{X}_{\mathrm{EPP}}^{\circ}\right]$ feature on the Int $^{\circ}$ head. This loss may also be explained within a cue-based approach to acquisition and change, similar to what was argued for the loss of verb movement to $\mathrm{Foc}^{\circ}$ in questions with monosyllabic $w h$-words in the previous section. As the monosyllabic (and disyllabic) $w$ h-elements drift towards a status as heads, there will be an increasing frequency of wh-questions with non-V2 word order in the input to children, especially since these types of $w$ h-questions seem to be generally much more frequent than questions introduced by complex $w h$-phrases. According to the figures in Table 1 in section 3.1 above, there are 889 questions with monosyllabic $w h$-elements out of a total of $990 w h$-questions attested in the speech sample from the parents in the acquisition corpus, which makes up $89.8 \%$. In comparison, questions introduced by disyllabic question words are attested in $5.2 \%$ of the data (51 occurrences), while longer $w$ h-phrases only appear in $5.1 \%$ of all questions (50 occurrences). This means that when V2 is lost in questions with monosyllabic $w h$-words, the evidence for verb movement in $w h$-questions will only rarely be expressed in the input to children. When the cue for V2 word order falls below a critical level in the primary linguistic data that children are exposed to, they will ignore it. The result of this would be a reorganization of the grammar and as a consequence, a complete loss of verb movement to the $\operatorname{Int}^{\circ}$ head in $w h$-questions.

The result of such a change would mean that the structural representation of the IntP would be as in the Nordmøre dialect, as was illustrated in (32) above. According to Lightfoot (1999), such a parameter change should lead to 'catastrophes' in the grammars (as opposed to gradualism), meaning that we should see major effects of this in the E-language (the language actually produced by the speakers). However, in the case of verb movement, this catastrophic change in the internalized grammar of the speakers may be masked by the existence of the FocP. This means that even after the [Int $\left.{ }^{\circ} \mathrm{EPP}\right]$ feature has been completely lost, speakers may continue to produce a considerable number of sentences with V2 word order. This would then be the result of verb movement to the $\mathrm{Foc}^{\circ}$ head, and consequently, it should only occur in questions where the subject is informationally new, i.e. [+foc]. This is presumably the case in the Nordmøre dialect. ${ }^{12}$ In the Kåfjord dialect, on the other hand, there is no evidence in the speech of the speakers investigated here that the dialect has reached 
that stage yet. The reason for this is that V2 seems to be the default word order in questions with longer $w h$-phrases. However, given the sociolinguistic perspective which assumes that the dialect is in fact developing from non-V2 to V2, it is also possible to interpret the occasional examples of non-V2 in the same way as was suggested for the disyllabic question words above. This means that these examples could be considered remnants of a grammar where the $\left[\mathrm{X}_{\mathrm{EPP}}^{\circ}\right]$ feature on the $\mathrm{Int}^{\circ}$ head had been completely lost, but where this development has now been reversed in the I-language of the speakers.

\section{SUMMARY AND CONCLUSION}

In this paper I have investigated the word order of $w h$-questions in a dialect spoken in Kåfjord in North Norway and made a comparison with findings for the Troms $\emptyset$ dialect reported in Westergaard (2003). While the choice of word order (V2 or non-V2) in the Troms $\varnothing$ speech sample is clearly dependent on information structure, it has been shown here that the Kåfjord speakers produce considerably more non-V2 word order in questions with monosyllabic wh-elements, while V2 only occurs in special cases, mainly with the verb 'be'. In questions with multisyllabic wh-constituents, on the other hand, the overwhelming majority of cases occur with V2. There also seems to be a certain difference in the frequency of non-V2 between questions introduced by disyllabic $w h$-words and longer $w h$-phases.

This synchronic variation is given a diachronic analysis within a Split-CP model of clause structure and a cue-based approach to acquisition and change. In the syntactic model, V2 in wh-questions may be the result of verb movement to the head of either the Int(errogative)P or the Foc(us)P in the CP domain. The latter type of verb movement only takes place when the subject of the sentence is informationally new. A Head Preference drift (van Gelderen 2004a, b) causes the monosyllabic wh-words to be reanalyzed as heads, which then move into Int $^{\circ}$, thus blocking verb movement. In such cases the verb may only move to $\mathrm{Foc}^{\circ}$, which accounts for V2 word order occurring in the Troms $\varnothing$ dialect with focused subjects only. As subjects generally tend to be given information, the occurrence of non-V2 word order will increase, and as argued in Westergaard (forthcoming) for similar changes in the history of English, this creates an information structure drift towards non-V2, eventually causing the cue for verb movement to fall below a critical level in the input to children. Using the cue-based approach of Lightfoot (1999), I argue that this will result in loss of verb movement also to the $\mathrm{Foc}^{\circ}$ head, and V2 therefore survives only in lexically marked cases in the Kåfjord dialect, i.e. with the verb 'be' (as in non-subject-initial declaratives in present-day English).

The non-V2 word order occasionally attested in questions with disyllabic whwords in the Kåfjord speech sample is argued to be due to the Head Preference 
drift spreading to these $w h$-elements. This is presumably also affected by the lack of frequency of the longer $w h$-words compared to the monosyllabic ones in the input to children. This means that there would be verb movement to the $\operatorname{Foc}^{\circ}$ head also in these cases, accounting for the information structure patterns seen in the data. Finally, when non-V2 occurs in questions with longer wh-elements, this is argued to be due to a complete loss of verb movement to the Int $^{\circ}$ head. Again this is caused by children ignoring the cue for verb movement, as the frequency drops below a critical level in the primary linguistic data that they are exposed to. This final change may not have taken place yet in the grammar of the speakers investigated, who produce only a few such sentences in the corpus. However, another plausible analysis is that these changes have already occurred in the dialect, but that the process of development has been reversed due to external, sociolinguistic factors. In that case, the occasional examples produced in this corpus could be seen as remnants of such a system, and this would explain why non-V2 only survives in the typical cases (pronominal subjects, verbs other than 'be').

The following is a summary of the natural drift from V2 to non-V2 word order in Norwegian dialects outlined in this paper, with some sociolinguistic aspects taken into account:

Stage 1: $\quad$ V2 (Old Norse/Standard Norwegian), verb movement to Int ${ }^{\circ}$.

Stage 2: $\quad$ Monosyllabic $w h$ reanalyzed as heads $\Rightarrow$ Verb movement to Foc $^{\circ}$ (new subjects only) in questions $\mathrm{w} /$ monosyllabic $w h$, otherwise to Int $^{\circ}$.

○ Process REVERSED in Troms $\varnothing$ due to sociolinguistic pressure from standard Norwegian.

Stage 3: Head status spreads to disyllabic $w h$ (head drift + frequency of input) $\Rightarrow$ Verb movement to $\mathrm{Foc}^{\circ}$ also with disyllabic $w h$.

Stage 4: Information structure drift towards non-V2 with monosyllabic $w h \Rightarrow$ Loss of verb movement to $\mathrm{Foc}^{\circ} \Rightarrow \mathrm{V} 2$ survives in lexically marked cases (e.g. only with 'be').

○ Process (from stage 2 to 4) ACCELERATED in Kåfjord due to language contact (early 20th century).

Stage 5: Frequency of cue for V2 falls below critical level $\Rightarrow$ Loss of verb movement to $\mathrm{Int}^{\circ} \Rightarrow$ non-V2 also with multisyllabic wh-phrases

O Process REVERSED in Kåfjord due to sociolinguistic pressure from standard Norwegian and other dialects in the area.

In conclusion, the optionality of word order attested in the Troms $\varnothing$ and Kåfjord dialects is given a diachronic analysis within a theory of language acquisition and language change, where both economy principles (such as head preference) and frequency of input cues play an important role. It has also been argued that the gradualism seen in this development is due to several 'catastrophic' changes in microparameters (phrase to head, loss of verb movement to $\operatorname{Int}^{\circ}$ ), but that these are 
masked by verb movement still applying to a lower head in the CP domain (the Foc $^{\circ}$ head).

\section{ACKNOWLEDGEMENTS}

I would like to thank Jan Terje Faarlund, Hilde Sollid, Øystein Alexander Vangsnes and two anonymous reviewers for helpful comments on a previous version of this paper. All mistakes and inaccuracies that remain are my own responsibility.

\section{NOTES}

1. The acquisition corpus consists of altogether 70 one-hour recordings of three children. Apart from ten files recorded and transcribed by the present author, the corpus has been collected by Merete Anderssen.

2. I use the terms given and new information relatively informally here to refer to context, and with Chafe (1976:30), define given information as 'knowledge which the speaker assumes to be in the consciousness of the addressee at the time of the utterance'. In Westergaard (2005a), the two subject types are distinguished by a focus feature, given subjects being [-foc] and informationally new subjects [+foc]. See also section 4 below.

3. Sollid [=Nilsen] (2003) has also found that non-V2 word order in non-subject-initial declarative sentences is considered grammatical by older speakers of this dialect. To my knowledge, this has not been attested in any other dialect of Norwegian and is therefore presumably a clear result of language contact.

4. In addition to these non-subject questions, the mother produces 31 subject questions with $\mathrm{ka}$ 'what' and 138 with $\mathrm{kem}$ 'who', while corresponding figures for the father are 7 and 17. Additionally, the mother produces one subject question with the wh-phrase korsn NP (som) 'which (lit. how) NP ...'. Subject questions are special in dialects that allow non$\mathrm{V} 2$ in that there is generally a syntactic requirement for the relative complementizer som in second position of the clause. Subject questions will not be discussed in this paper. However, let us note that the parents each produce three subject kem-questions without this complementizer. This corresponds to a finding in Nilsen (1996) that speakers of the Nordreisa dialect to a certain extent accept subject questions without som.

5. In this article the examples are provided exactly as they have been transcribed in the corpus. As there is no standard spelling for the dialect versions of the various question words, different spellings occur in the corpus, e.g. korsen/korsn 'how' or korfor/koffer/koff $\phi r$ 'why'.

6. The examples from the corpus produced by the two parents are marked FAT and MOT for father and mother, respectively.

7. The male speaker may represent a more conservative version of the Troms $\emptyset$ dialect, similar to what was found in the Kåfjord data.

8. The data in Westergaard (forthcoming) are based on a corpus investigated in Bech (2001).

9. In Westergaard (forthcoming) I also argue that the initial change from a V2 to a non-V2 grammar in the history of English is caused by young children's early sensitivity to patterns 
of information structure. This is based on findings from Norwegian child language where consistent V2 in non-subject-initial declaratives in the input is initially misanalyzed as verb movement that only applies when the subject is informationally new, see also Westergaard (2004, 2005a).

10. It should be noted that the female Kåfjord speaker recognized the non-V2 word order in questions with multisyllabic wh-elements as typical of the dialect. However, this also seems to be a stigmatized feature that younger speakers may not wish to identify with, see also Nilsen (1996) and Sollid (2003).

11. In Westergaard (forthcoming), where I provide an analysis for the loss of V2 in nonsubject-initial declaratives in Old and Middle English, I argue that pragmatic factors play an important role, see also Bech (2001) and Haukenes (1998).

12. To my knowledge, no empirical investigation has been carried out in the Nordmøre dialect on the use of V2 vs. non-V2 word order related to information structure. Åfarli (1986) observes that non-V2 word order is more acceptable if the subject is short (often a pronoun), while V2 is preferred if the subject is heavy. I take this to be an indication that pragmatic factors govern the choice of word order in this dialect too.

\section{REFERENCES}

Åfarli, Tor. 1985. Absence of V2 effects in a dialect of Norwegian. Working Papers in Scandinavian Syntax 22, 1-21. University of Stockholm.

Åfarli, Tor. 1986. Some syntactic structures in a dialect of Norwegian. Working Papers in Linguistics 3, 93-111. University of Trondheim.

Bech, Kristin. 2001. Word Order Patterns in Old and Middle English: A Syntactic and Pragmatic Study. Dr. art. dissertation, University of Bergen.

Birner, Betty. 1995. Pragmatic constraints on the verb in English inversion. Lingua 97, 233-256.

Bresnan, Joan \& Tatiana Nikitina. 2003. On the gradience of the dative alternation. Ms., Stanford University.

Chafe, Wallace L. 1976. Givenness, contrastiveness, definiteness, subjects, topics, and point of view. In Charles N. Li (ed.), Subject and Topic. New York: Academic Press, 27-55.

Firbas, Jan. 1992. Functional Sentence Perspective in Written and Spoken Discourse. Cambridge \& New York: Cambridge University Press.

Fiva, Toril. 1996. Spørresetninger i Troms $\varnothing$ dialekten [Interrogative clauses in the Troms $\varnothing$ dialect]. Nordica Bergensia 9, 139-155.

Gelderen, Elly van. 2004a. Economy, innovation, and prescriptivism: From Spec to Head and Head to Head. Journal of Comparative Germanic Linguistics 7, 59-98.

Gelderen, Elly van. 2004b. Grammaticalization as Economy. Amsterdam \& Philadelphia: John Benjamins.

Haukenes, Ella. 1998. Inversion in English: A Diachronic Study. Dr. art. dissertation, University of Troms $\varnothing$.

Hinterhölzl, Roland. 2005. Language change versus grammar change: What diachronic data reveal about the distinction between core grammar and periphery. In Eric Fuß \& Carola Trips (eds.), Diachronic Clues to Synchronic Grammar. Amsterdam \& Philadelphia: John Benjamins, 131-160. 
Hróarsdóttir, Thorbjörg. 2002. Explaining language change: a three-step process. Papers from the Workshop 'Language Change from a Generative Perspective' (Linguistics in Potsdam 19), 103-141.

Hróarsdóttir, Thorbjörg. 2004. Cues and expression. Nordlyd 32.1: Troms $\phi$ Working Papers in Language Acquisition, 135-155.

Lie, Svein. 1992. Ka du sei? [What are you saying?], Maal og Minne 1992, 62-77.

Lightfoot, David. 1999. The Development of Language: Acquisition, Change and Evolution. Malden, MA \& Oxford: Blackwell.

Lightfoot, David. Forthcoming. How New Languages Emerge. Cambridge: Cambridge University Press.

Nilsen, Hilde. 1996. Koff $\phi r$ dem sir det? [Why do they say that?] Cand. philol. thesis, University of Tromsø.

Nordgård, Torbjørn. 1985. Word Order, Binding and the Empty Category Principle. Cand. philol thesis, University of Trondheim.

Rice, Curt \& Peter Svenonius. 1998. Prosodic V2 in Northern Norwegian. Ms., University of Tromsø.

Rizzi, Luigi. 1997. The fine structure of the left periphery. In Liliane Haegeman (ed.), Elements of Grammar: Handbook of Generative Syntax. Dordrecht: Kluwer, 281-337.

Rizzi, Luigi. 2001. On the position 'Int(errogative)' in the left periphery of the clause. In Guglielmo Cinque \& Giampolo Salvi (eds.), Current Studies in Italian Syntax. Amsterdam: Elsevier, 287-296.

Sollid, Hilde. 2003. Dialektsyntaks i Nordreisa: Språkdannelse og stabilisering i møtet mellom kvensk og norsk [Dialect syntax in Nordreisa: language creation and stabilization in a contact situation between Kven-Finnish and Norwegian]. Dr. art. dissertation, University of Troms $\varnothing$.

Taraldsen, Knut Tarald. 1985. Ka du trur? [What do you think?]. In Tove Bull \& Anton Fjellstad (eds.), Heiderskrift til Kåre Elstad [Festschrift for Kåre Elstad]. University of Troms $\varnothing, 37-47$.

Taraldsen, Knut Tarald. 1986. On verb second and the functional content of syntactic categories. In Hubert Haider \& Martin Prinzhorn (eds.), Verb Second Phenomena in Germanic Languages Dordrecht: Foris, 7-25.

Vangsnes, Øystein Alexander. 2004. On wh-questions and V2 across Norwegian dialects: a survey and some speculations. Working Papers in Scandinavian Syntax 73, 1-59.

Vikner, Sten. 1995. Verb Movement and Expletive Subjects in the Germanic Languages. New York \& Oxford: Oxford University Press.

Westergaard, Kristin M. 2005. En studie av ordstillingen i $h v$-spørsmål blant ungdom i Troms $\emptyset$ [A study of the word order in $w h$-questions among young people in Troms $\varnothing$ ]. Project paper in Norwegian language, Kongsbakken videregående skole, Troms $\emptyset$.

Westergaard, Marit R. 2003. Word order in wh-questions in a North Norwegian dialect: some evidence from an acquisition study. Nordic Journal of Linguistics 26.1, 81109.

Westergaard, Marit R. 2004. The interaction of input and UG in the acquisition of Verb Movement in a dialect of Norwegian. Nordlyd 32.1: Troms $\phi$ Working Papers in Language Acquisition, 110-134.

Westergaard, Marit R. 2005a. The Development of Word Order in Norwegian Child Language: The Interaction of Input and Economy Principles in the Acquisition of V2. Dr. philos. dissertation, University of Troms $\emptyset$. 
Westergaard, Marit R. 2005b. Unlearning V2: the role of L1 acquisition in the loss of verb movement in the history of English and present-day Norwegian dialects. Ms., University of Troms $\varnothing$. Paper presented at Sonderforschungsbereich Mehrsprachigkeit, Universität Hamburg, 12 May 2005.

Westergaard, Marit R. Forthcoming. Norwegian child language and the history of English: the interaction of syntax and information structure in the development of word order. In Kevin McCafferty, Tove Bull \& Kristin Killie (eds.), Contexts - Historical, Social, Linguistic: Studies in Celebration of Toril Swan. Bern: Peter Lang, 293-410.

Westergaard, Marit R. \& Øystein Alexander Vangsnes. 2005. Wh-questions, V2, and the left periphery of three Norwegian dialects. Journal of Comparative Germanic Linguistics $\mathbf{8}$, $119-160$. 